\title{
Early catecholamine dose as a predictor of outcome among patients in a multidisciplinary intensive care unit
}

\author{
M Agael, MB BCh, FCP (SA); K de Vasconcellos, MB ChB, DA (SA), FCA (SA), Cert Critical Care (SA); \\ D Skinner, Cert Critical Care (SA), MMed (Surgery), FCS (SA), MB ChB
}

Intensive Care Unit, Department of Internal Medicine, Nelson R Mandela School of Medicine, University of KwaZulu-Natal, Durban, South Africa

Corresponding author: M Agael (muniragael@gmail.com)

\begin{abstract}
Background. Vasoactive and/or inotropic agents are used in the management of patients with circulatory shock. It is a clinical perception that mortality in critically ill patients increases with increasing doses of inotropes and/or vasopressors; however, the clinical significance of catecholamine doses early in the management of critically ill patients has not been investigated well, especially in the South African (SA) context. Arbitrary 'maximum' doses of catecholamine therapy are used that are not evidence based. This study will help clinicians by either showing that there is no clear cut-off beyond which survival is unlikely or by identifying a dose of inotropic support above which survival is unlikely. This article provides clinicians with an evidence base against which to direct their therapy.

Objectives. To describe the inotropic prescribing practices in a heterogeneous population of shocked critically ill patients in a tertiary intensive care unit (ICU) in SA, establish an association between inotropic dose and outcome and ascertain the nature of this association. Methods. This was a retrospective observational study of 189 patients admitted to a multidisciplinary academic ICU. The admission, 24-hour and maximum inotrope doses were collected and analysed, and these and other biochemical and clinical parameters were evaluated as predictors of mortality.

Results. A total of 189 patients met the study inclusion criteria. The overwhelming majority of patients (99\%) received adrenaline, with only $7 \%$ of those requiring inotropes receiving noradrenaline. Median inotrope dose at admission, 24-hour dose and maximum dose in the first 24 hours were all significantly higher in non-survivors than survivors. ICU mortality increased with increasing inotrope dose, and an inotrope dose $\geq 60 \mu \mathrm{g} / \mathrm{min}$ on admission was associated with an ICU mortality of $89 \%$, with the same cut-off at 24 hours being associated with a mortality of $89 \%$. Survivors at doses $>80 \mu \mathrm{g} / \mathrm{min}$ were only noted among trauma patients.

Conclusions. High early inotrope doses are associated with increasing ICU mortality. The findings highlight the need for further research on the clinical use of inotrope dose in risk stratification in the critical care environment. The current results call into question the routine provision of high-dose inotropic support in non-trauma patients.
\end{abstract}

S Afr Med J 2021;111(7):674-679. https://doi.org/10.7196/SAMJ.2021.v111i7.14385

Critically ill patients frequently require inotropic and/or vasopressor support to treat circulatory shock. Subtypes of circulatory shock include hypovolaemic, cardiogenic, obstructive (e.g. pulmonary embolus, tension pneumothorax) and distributive (e.g. septic, neurogenic) shock. Patients with cardiogenic shock or a cardiogenic component to their shock state are frequently treated with dobutamine, an agent with positive inotropic effects and a mild net vasodilatory effect, an 'inodilator. ${ }^{[1]}$ Most other forms of shock are treated with noradrenaline or adrenaline. Both these agents have positive inotropic and vasoconstrictive effect 'inopressors. ${ }^{[1]}$ Noradrenaline is recommended as first-line therapy in septic shock. However, due to the limited availability of noradrenaline in South Africa (SA), adrenaline is frequently used in lieu of the former. ${ }^{[2]}$

Clinical experience suggests that mortality in critically ill patients increases with increasing doses of inotropes and/or vasopressors. Critical care physicians are often faced with determining a threshold of inopressor support, above which rescue therapy is required or where survival is unlikely. The literature to help to determine these thresholds is limited. An inotrope dose is a component of the Sequential Organ Failure Assessment (SOFA) score, which has been found to correlate with intensive care unit (ICU) mortality. ${ }^{[3,4]}$ The cardiovascular component of the score, however, only differentiates between a dose of $\leq 0.1 \mu \mathrm{g} / \mathrm{kg} / \mathrm{min}$ or $>0.1 \mu \mathrm{g} / \mathrm{kg} / \mathrm{min}$ of adrenaline or noradrenaline. These doses are relatively low and are not a clinically relevant threshold. A few studies have specifically explored the relationship between catecholamine dose and patient survival in critical care. Benbenishty et al..$^{[5]}$ reported survival of only $4 \%$ in patients receiving $>0.5 \mu \mathrm{g} / \mathrm{kg} / \mathrm{min}$ of inotropic support, Jenkins et al..$^{[6]}$ found that only $3.3 \%$ of patients receiving $>100 \mu \mathrm{g} / \mathrm{min}$ of noradrenaline survived, Sviri et al. ${ }^{[7]}$ showed a mortality rate of $84 \%$ in patients receiving $>40 \mu \mathrm{g} / \mathrm{min}$ of inotropic support, and Brown et al ${ }^{[8]}$ reported a mortality rate of $83 \%$ in patients receiving $\geq 1 \mu \mathrm{g} / \mathrm{kg} / \mathrm{min}$. In contrast, Auchet et al..$^{[9]}$ reported a survival rate of $39.6 \%$ in patients receiving $>1 \mu \mathrm{g} / \mathrm{kg} / \mathrm{min}$, with Döpp-Zemel and Groeneveld ${ }^{[10]}$ noting a similar survival rate of $34.5 \%$ in patients receiving $\geq 0.9 \mu \mathrm{g} / \mathrm{kg} / \mathrm{min}$.

The disparate findings presented above make it difficult for physicians treating critically ill patients to take evidence-based decisions. This is further compounded by the abovementioned studies having been conducted in high-income countries, and it is unclear whether the results are applicable to low- and middle-income countries. Potential differences include those regarding drug availability (e.g. limited availability of noradrenaline in SA), ICU bed availability and triage and patient profile, including a young age and an increased incidence of HIV and sepsis in sub-Saharan Africa and SA specifically. ${ }^{[11-14]}$

It is therefore important to evaluate the inotrope prescribing practices in the SA context, and to establish whether there is an association between dose and patient outcome. This will allow for improved evidence-based quality of care for critically ill SA patients. 


\section{Methods}

This was a retrospective observational study of patients admitted to a multidisciplinary, closed, intensivist-run ICU in a tertiary academic hospital that serves the province of KwaZulu-Natal in SA.

All adult ( $\geq 18$ years) patients requiring inotropic support with adrenaline or noradrenaline to maintain a mean arterial pressure $>70 \mathrm{mmHg}$ within the first 24 hours of ICU admission, were eligible for inclusion. The exclusion criteria were as follows: children (age $<18$ years), use of dobutamine, cardiogenic shock/refractory cardiac failure or documentation of a significant cardiogenic component in the setting of mixed forms of shock. Dobutamine use was excluded owing to lack of dose equivalency with the dominant catecholamines used in the study ICU, and owing to its drug-specific effects that prevent a direct pharmacological comparison between dobutamine and adrenaline/noradrenaline. Cardiogenic shock/refractory cardiac failure was an exclusion, as dobutamine is the catecholamine of choice in this condition. Data collection proceeded backwards from the date of ethical approval, with patients admitted from May 2016 to June 2018 included in the study.

Based on previous study data, using an alpha of 0.05 , a power of $80 \%$ and an anticipated ratio of patients with high-dose:low-dose inotropic support of 0.2 , a sample size of 112 was calculated. ${ }^{[9]}$ It was unclear how appropriate the values used in the sample size calculation were for the study ICU (i.e. effect size and enrolment ratio) and it was therefore decided to use a sample size of 200 or include patients over a 2-year period, whichever came first. This would be logistically feasible, while allowing for a margin of safety, given the unknown factors discussed above.

Statistical analysis was performed using SPSS version 25.0 (IBM Corp., USA) and MedCalc Statistical Software version 18.10.2 (MedCalc, Belgium).The categorical variables were described as percentages and compared using the $\chi^{2}$ test or Fisher's exact test, where appropriate. Continuous data were described using mean and standard deviation (SD) when normally distributed, and median and interquartile range (IQR) when the distribution was non-Gaussian. These data were compared using the independent samples $t$-test, Mann-Whitney $U$-test or Kruskal-Wallis test, respectively. Receiver operating characteristic (ROC) curves were constructed for inotrope dose and ICU mortality. The optimal cut-off point for each inotrope dose was determined by identifying the points on the curve closest to the (0.1) corner. These cut-off points were then combined with commonly considered clinical cut-off points, and the performance of each cut-off compared by determining the sensitivity, specificity, positive predictive value (PPV), negative predictive value (NPV), positive likelihood ratio (PLR), and negative likelihood ratio (NLR). Where appropriate, the areas under the ROC curve (AUC) was compared using the method described by DeLong et al. ${ }^{[15]}$

\section{Ethical approval}

Ethical approval was granted by the University of KwaZulu-Natal Biomedical Research Ethics Committee (ref. no. BE052/18), the study hospital and the KwaZulu-Natal Department of Health (ref. no. HRKM099/18).

\section{Results}

The derivation of the study cohort is shown in Fig. 1. The final study population included 189 patients who required inotropic support with adrenaline and/or noradrenaline during the first 24 hours of ICU admission.

Table 1 shows the baseline demographic, organ dysfunction, outcome and inotrope data for the cohort, and provides univariate analyses between these variables and ICU mortality. Patients were not

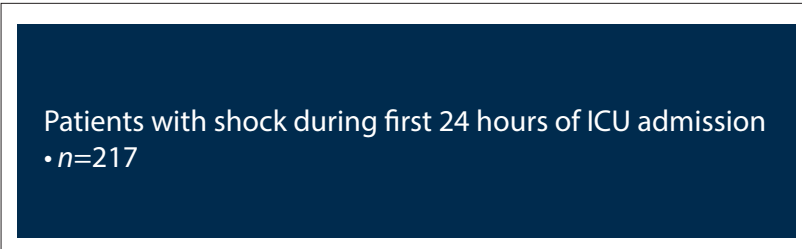

Patients excluded

- Age: $<18$ years, $n=12$

- Dobutamine use, $n=14$

- Transferred to another ICU (no outcome available), $n=2$

Patients included

$\cdot n=189$

- Survived, $n=96(50.8 \%)$

- Died, $n=93(49.2 \%)$

Fig. 1. Derivation of study cohort. (ICU = intensive care unit.)

classified according to the 'type' of shock they exhibited, with those with suspected cardiogenic shock being excluded from the analysis; the included patients comprised mainly hypovolaemic/haemorrhagic shock and/or septic shock. In all cases, noradrenaline was the second inotrope.

The admission, 24-hour and maximum inotrope doses were all significantly higher in non-survivors than survivors (Table 1). Fig. 2 shows the ROC curve analyses for the abovementioned inotrope doses and ICU mortality. The AUC for the admission inotrope dose was 0.67 (95\% confidence interval (CI) $0.59-0.76 ; p<0.001$ ), for the 24-hour inotrope dose 0.76 ( $95 \%$ CI $0.69-0.84 ; p<0.001$ ) and for the maximum inotrope dose within 24 hours 0.75 (95\% CI 0.68 - 0.83). The AUC for the admission inotrope dose was significantly lower than for the 24-hour $(p=0.042)$ and maximum $(p=0.021)$ inotrope doses.

The ROC curves were used to select potential optimum cut-off points for inotrope doses; their performance and common clinical cut-off points are presented in Table 2. For a cut-off of $60 \mu \mathrm{g} / \mathrm{min}$, the PPV for mortality approaches $90 \%$ for both admission and 24-hour inotropic requirements.

Table 3 shows the subgroup analyses for inotrope doses and ICU outcome according to the primary admission diagnosis. Median inotrope doses were significantly higher in non-survivors at all points and in all subgroups, except for trauma patients on admission.

Figs 3, 4 and 5 illustrate plots of inotrope doses and ICU outcomes by primary diagnosis. The maximum inotrope dose in survivors with non-communicable disease was $67 \mu \mathrm{g} / \mathrm{min}, 80 \mu \mathrm{g} / \mathrm{min}$ in sepsis and $143 \mu \mathrm{g} / \mathrm{min}$ in trauma.

\section{Discussion}

The ICU at which the study took place treats a notably young cohort of patients with a high incidence of trauma and infectious disease. ${ }^{[3]}$ The cohort had a high severity of illness, as evidenced by the admission SOFA score, and consequently a high mortality rate. The study included a heterogenous group of medical, surgical and obstetric patients with a spectrum of infectious, traumatic and noncommunicable primary pathological conditions. Patients were not classified according to type of shock due to the many contributing factors to shock in any patient; however, if a significant cardiogenic component was known or suspected, such patients were excluded 
Table 1. Summary data for cohort and univariate analyses for ICU outcome

\begin{tabular}{|c|c|c|c|c|c|}
\hline Variable & Characteristics & $\begin{array}{l}\text { Total, median } \\
(\mathrm{IQR})^{\star}\end{array}$ & $\begin{array}{l}\text { Survived }(n=96) \\
\text { median }(I Q R)^{*}\end{array}$ & $\begin{array}{l}\text { Died }(n=93) \\
\text { median }(I Q R)^{*}\end{array}$ & $p$-value \\
\hline \multirow[t]{2}{*}{ Age, years } & & 40 & 35 & 44 & 0.006 \\
\hline & & $(28.0-59.0)$ & $(27.0-53.0)$ & $(32.0-63.0)$ & \\
\hline Female, $n(\%)$ & & $95(50.3)$ & $47(49.0)$ & $48(51.6)$ & 0.715 \\
\hline \multirow[t]{3}{*}{ Admission discipline, $n(\%)$} & $\mathrm{O} \& \mathrm{G}$ & $19(10.1)$ & $12(12.5)$ & $7(7.5)$ & 0.519 \\
\hline & Medical & $76(40.2)$ & $38(39.6)$ & $38(40.9)$ & \\
\hline & Surgical & $94(49.7)$ & $46(47.9)$ & $48(51.6)$ & \\
\hline \multirow[t]{3}{*}{ Primary diagnosis, $n(\%)$} & Sepsis & $68(36.0)$ & $28(29.2)$ & $40(40.0)$ & 0.088 \\
\hline & Trauma & $47(24.9)$ & $29(30.2)$ & $18(19.4)$ & \\
\hline & Non-communicable & $74(39.2)$ & $39(40.6)$ & $35(37.6)$ & \\
\hline Postoperative, $n(\%)$ & & $103(54.5)$ & $56(58.3)$ & $47(50.5)$ & 0.282 \\
\hline Mechanical ventilation (1st 24 hours), $n$ (\%) & & $189(100)$ & $96(100)$ & $93(100)$ & \\
\hline RRT (1st 24 hours), $n(\%)$ & & $16(8.5)$ & $6(6.3)$ & $10(10.8)$ & 0.266 \\
\hline Death within 24 hours, $n(\%)$ & & $20(10.6)$ & $0(0)$ & $20(21.5)$ & $<0.001$ \\
\hline Discharge within 24 hours, $n(\%)$ & & $1(0.5)$ & $1(1.0)$ & $0(0)$ & 0.324 \\
\hline ICU LOS & & $4.0(2.0-6.0)$ & $4.0(3.0-7.0)$ & $3.0(1.0-5.0)$ & $<0.001$ \\
\hline \multirow[t]{2}{*}{ SOFA score on admission } & & 11 & 11.0 & 12.0 & $<0.001$ \\
\hline & & $(10.0-13.0)$ & $(10.0-13.0)$ & $(10.0-14.0)$ & \\
\hline \multirow[t]{2}{*}{ SOFA score at 24 hours } & & 12.0 & 11.0 & 13.0 & $<0.001$ \\
\hline & & $(10.0-13.0)$ & $(9.0-12.0)$ & $(11.0-14.0)$ & \\
\hline AKI within first 24 hours, $n(\%)$ & & $77(41.0)$ & $31(32.3)$ & $46(50.0)$ & 0.014 \\
\hline \multirow[t]{3}{*}{ Inotrope 1 on admission, $n(\%)$} & Adrenaline & $184(97.4)$ & $93(96.9)$ & $91(97.8)$ & 0.857 \\
\hline & Noradrenaline & $2(1.1)$ & $1(1.0)$ & $1(1.1)$ & \\
\hline & Nil & $3(1.6)$ & $2(2.1)$ & $1(1.1)$ & \\
\hline Use of second inotrope on admission, $n(\%)$ & & $10(5.3)$ & $0(0)$ & $10(10.8)$ & 0.001 \\
\hline \multirow[t]{3}{*}{ Inotrope 1 at 24 hours, $n(\%)$} & Adrenaline & $148(88.1)$ & $80(84.2)$ & $68(93.2)$ & 0.062 \\
\hline & Noradrenaline & $1(0.6)$ & $0(0)$ & $1(1.4)$ & \\
\hline & Nil & $19(11.1)$ & $15(15.8)$ & $4(5.5)$ & \\
\hline Use of second inotrope at 24 hours, $n(\%)$ & & $10(6.0)$ & $2(2.1)$ & $8(11.0)$ & 0.016 \\
\hline \multirow[t]{2}{*}{ Total admission inotrope dose, $\mu \mathrm{g} / \mathrm{min}$} & & 20.0 & 13.3 & 26.7 & $<0.001$ \\
\hline & & $(13.3-40.0)$ & $(6.7-26.7)$ & $(13.3-60.0)$ & \\
\hline \multirow[t]{2}{*}{ Total 24-hour inotrope dose, $\mu \mathrm{g} / \mathrm{min}$} & & 13.3 & 6.7 & 34.7 & $<0.001$ \\
\hline & & $(4.0-40.0)$ & $(2.7-16.0)$ & $(10.7-66.7)$ & \\
\hline \multirow{2}{*}{$\begin{array}{l}\text { Maximum inotrope dose in first } 24 \text { hours, } \\
\mu \mathrm{g} / \mathrm{min}\end{array}$} & & 40.0 & 26.7 & 66.7 & $<0.001$ \\
\hline & & $(20.0-66.7)$ & $(13.3-40.0)$ & $(30.7-93.3)$ & \\
\hline $\begin{array}{l}\text { Non-escalation or withdrawal of inotropic } \\
\text { support during first } 24 \text { hours, } n(\%)\end{array}$ & & $3(1.6)$ & $3(3.1)$ & $0(0)$ & 0.086 \\
\hline
\end{tabular}

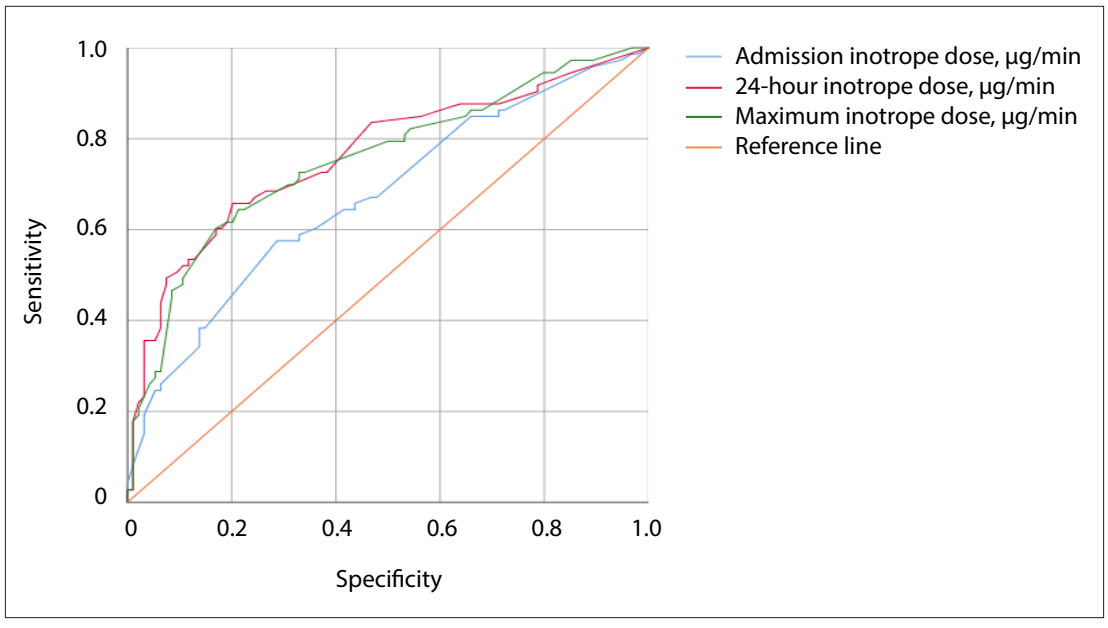

Fig. 2. Receiver operating characteristic curve for inotrope dose and intensive care unit mortality. from the study. The dominant inotrope used was adrenaline, with noradrenaline being used in a small subset of patients, which reflects its limited availability in SA.

It was expected that for patients with a poor prognosis, the treating intensivist may have limited the maximum inotrope dose, which would have introduced bias into the study. However, there were written instructions to limit inotropic support for only 3 patients during the first 24 hours of admission, and all survived to ICU discharge. This possibly reflects a reluctance among the treating physicians to limit inotropic support early in the course of critical illness until a trial period of active haemodynamic optimisation has been completed. 


\begin{tabular}{|c|c|c|c|c|c|c|c|}
\hline $\begin{array}{l}\text { Timing of inotropic } \\
\text { support }\end{array}$ & $\begin{array}{l}\text { Inotrope dose } \\
\text { cut-off, } \mu \mathrm{g} / \mathrm{min}\end{array}$ & Sensitivity, \% & Specificity, \% & NPV, \% & PPV, \% & PLR & NLR \\
\hline \multirow[t]{9}{*}{ Admission } & 7 & 88.2 & 27.1 & 70.3 & 53.9 & 1.21 & 0.44 \\
\hline & 13 & 84.9 & 33.3 & 69.6 & 55.2 & 1.27 & 0.45 \\
\hline & 21 & 62.4 & 62.5 & 63.2 & 61.7 & 1.66 & 0.60 \\
\hline & 25 & 60.2 & 69.8 & 64.4 & 65.9 & 1.99 & 0.57 \\
\hline & 40 & 38.7 & 86.5 & 59.3 & 73.5 & 2.86 & 0.71 \\
\hline & 47 & 31.2 & 93.8 & 58.4 & 82.9 & 4.99 & 0.73 \\
\hline & 60 & 25.8 & 96.9 & 57.4 & 88.9 & 8.26 & 0.77 \\
\hline & 80 & 10.8 & 99.0 & 53.4 & 90.9 & 10.32 & 0.90 \\
\hline & 100 & 6.5 & 100 & 52.5 & 100 & $-{ }^{+}$ & 0.94 \\
\hline \multirow[t]{9}{*}{24 hours } & 7 & 83.6 & 53.2 & 80.6 & 58.1 & 1.79 & 0.31 \\
\hline & 13 & 72.6 & 62.8 & 74.7 & 60.2 & 1.95 & 0.44 \\
\hline & 21 & 65.8 & 79.8 & 75.0 & 71.6 & 3.25 & 0.40 \\
\hline & 25 & 58.9 & 83.0 & 72.2 & 72.9 & 3.46 & 0.50 \\
\hline & 40 & 47.9 & 92.6 & 69.6 & 83.3 & 6.44 & 0.56 \\
\hline & 47 & 38.4 & 93.6 & 66.2 & 82.4 & 6.01 & 0.66 \\
\hline & 60 & 34.2 & 96. & 65.5 & 89.3 & 10.73 & 0.68 \\
\hline & 80 & 21.9 & 97.9 & 61.7 & 88.9 & 10.30 & 0.80 \\
\hline & 100 & 15.1 & 98.9 & 60.0 & 91.7 & 14.16 & 0.86 \\
\hline \multirow[t]{9}{*}{ Maximum dose } & 7 & 96.8 & 10.4 & 76.9 & 51.1 & 1.08 & 0.31 \\
\hline & 13 & 94.6 & 19.8 & 79.2 & 53.3 & 1.18 & 0.27 \\
\hline & 21 & 83.9 & 44.8 & 74.1 & 59.5 & 1.52 & 0.36 \\
\hline & 25 & 81.7 & 49.0 & 73.4 & 60.8 & 1.60 & 0.37 \\
\hline & 40 & 71.0 & 69.8 & 71.3 & 69.5 & 2.35 & 0.42 \\
\hline & 47 & 64.5 & 80.2 & 70.0 & 75.9 & 3.26 & 0.44 \\
\hline & 60 & 53.8 & 89.6 & 66.7 & 83.3 & 5.16 & 0.52 \\
\hline & 80 & 32.3 & $95.8 \%$ & 59.4 & 88.2 & 7.74 & 0.71 \\
\hline & 100 & 21.5 & 97.9 & 56.3 & 90.9 & 10.32 & 0.80 \\
\hline
\end{tabular}

\begin{tabular}{|c|c|c|c|c|c|c|}
\hline Inotrope dose, $\mu \mathrm{g} / \mathrm{min}$ & Primary diagnosis & Survived, median (IQR) & $p$-value ${ }^{*}$ & Died, median (IQR) & $p$-value ${ }^{*}$ & $p$-value ${ }^{\dagger}$ \\
\hline \multirow[t]{6}{*}{ Admission } & Sepsis & 13.3 & 0.645 & 26.7 & 0.855 & 0.001 \\
\hline & & $(6.7-26.7)$ & & $(16.7-61.7)$ & & \\
\hline & Trauma & 16.0 & & 25.0 & & 0.135 \\
\hline & & $(10.7-26.7)$ & & $(13.3-66.7)$ & & \\
\hline & Non-communicable & 16.0 & & 26.7 & & 0.004 \\
\hline & & $(6.7-26.7)$ & & $(13.3-53.3)$ & & \\
\hline \multirow[t]{6}{*}{24 hours } & Sepsis & 5.3 & 0.475 & 21.3 & 0.066 & 0.001 \\
\hline & & $(2.7-11.3)$ & & $(8.0-73.3)$ & & \\
\hline & Trauma & 10.7 & & 66.7 & & $<0.001$ \\
\hline & & $(2.7-20.0)$ & & $(50.7-93.3)$ & & \\
\hline & Non-communicable & 6.7 & & 33.3 & & $<0.001$ \\
\hline & & $(1.3-18.7)$ & & $(13.3-60.0)$ & & \\
\hline \multirow[t]{6}{*}{ Maximum } & Sepsis & 19.3 & 0.166 & 66.7 & 0.248 & $<0.001$ \\
\hline & & $(11.3-26.7)$ & & $(24.0-105.0)$ & & \\
\hline & Trauma & 26.7 & & 73.3 & & 0.001 \\
\hline & & $(13.3-40.0)$ & & $(50.7-93.3)$ & & \\
\hline & Non-communicable & 26.7 & & 53.3 & & $<0.001$ \\
\hline & & $(16.0-48.0)$ & & $(26.7-66.7)$ & & \\
\hline
\end{tabular}




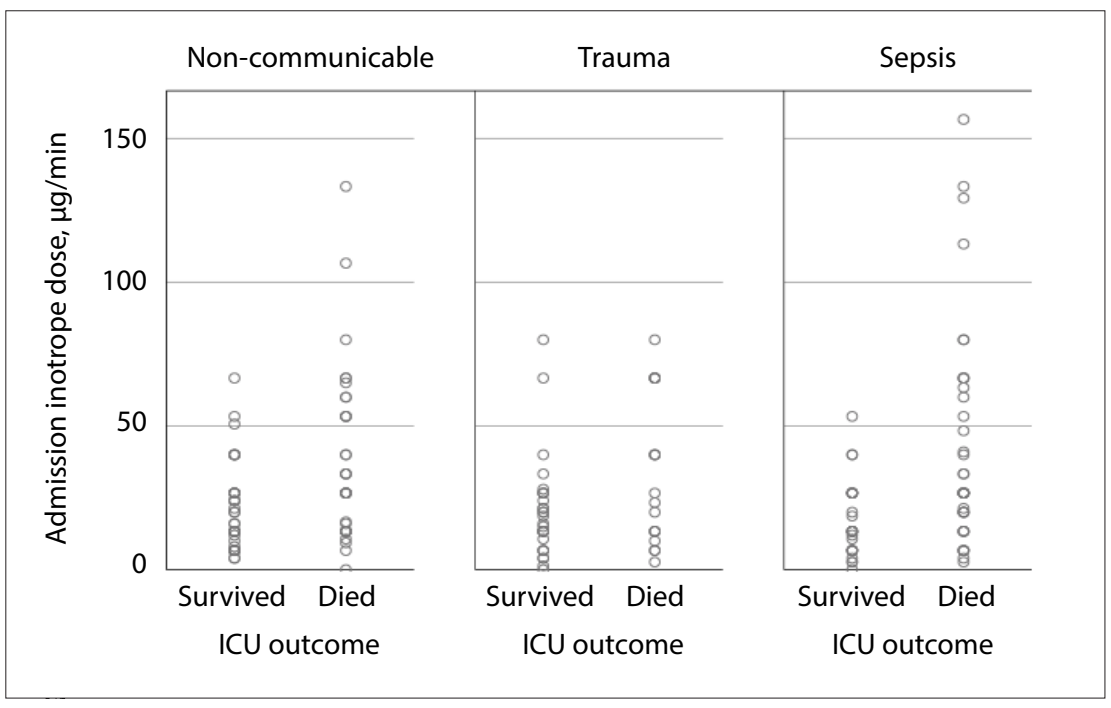

Fig. 3. Plots comparing admission inotrope dose and ICU outcome by primary diagnosis. (ICU = intensive care unit.)

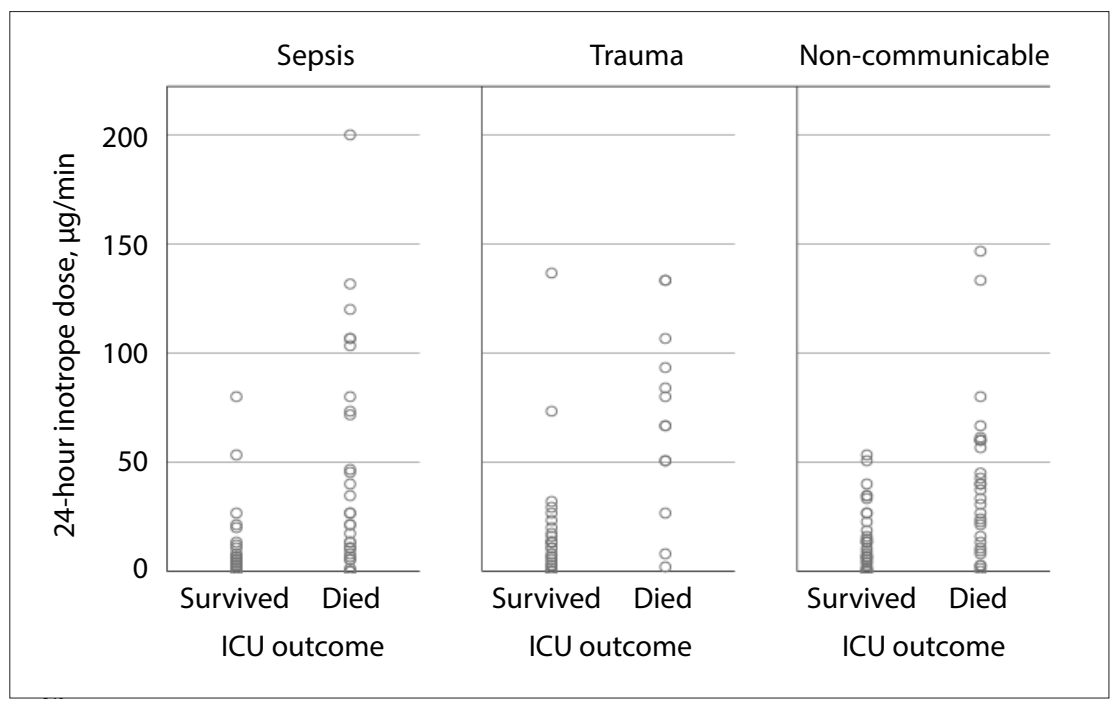

Fig. 4. Plots comparing 24-hour inotrope dose and ICU outcome by primary diagnosis. (ICU = intensive care unit.)

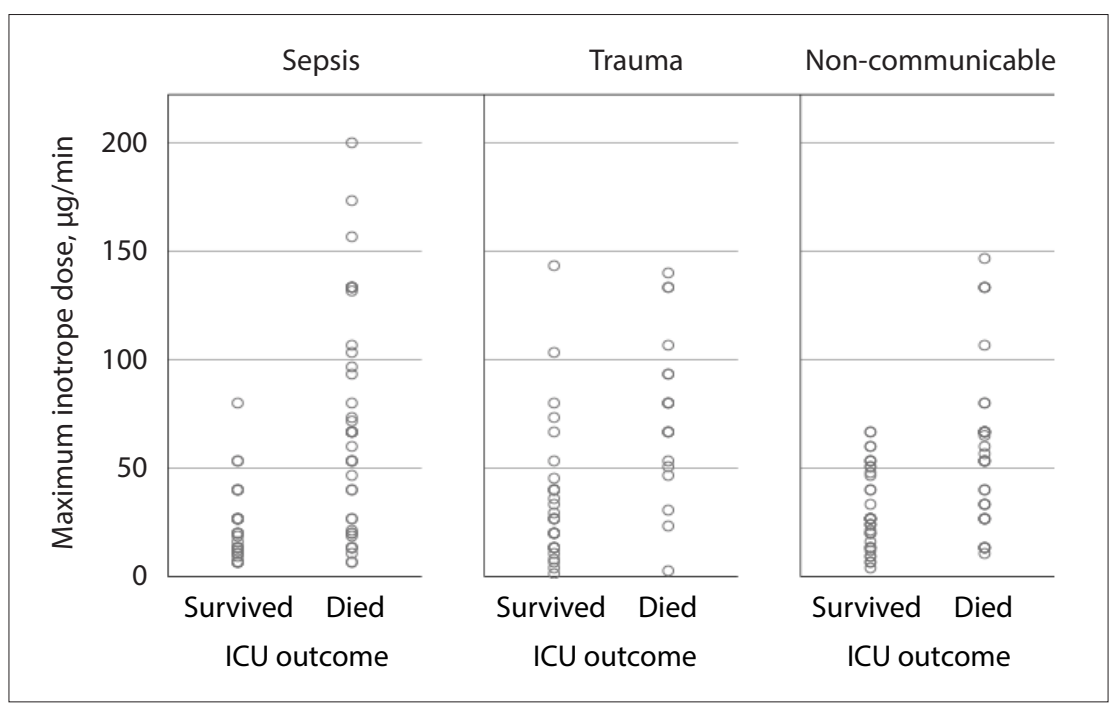

Fig. 5. Plots comparing maximum inotrope dose and ICU outcome by primary diagnosis. (ICU = intensive care unit.)
There was a statistically significant difference in the median inotrope dose between survivors and non-survivors for admission, 24-hour and maximum inotrope doses, which was an anticipated finding. The magnitude of the difference appeared more marked for 24-hour and maximum inotrope doses than for admission inotrope dose. Similarly, ROC curve analyses showed that inotrope dose was significantly associated with ICU mortality, with reasonable predictive accuracy. The performance of 24-hour and maximum inotrope doses was significantly better than for the admission inotrope dose.

While statistically significant, these findings do not necessarily provide the practising clinician with clinically relevant data. To this end, the performance of various inotropic cut-off points was evaluated (see Methods above) (Table 2). The NPV of low doses of inotropic support $(<13 \mu \mathrm{g} / \mathrm{min})$ is reasonably high $(\geq 70 \%)$, indicating that these patients are likely to survive ICU admission. This is particularly true if the inotrope dose remains low, with an NPV of $80.6 \%$ if inotropic support at 24 hours is $<7 \mu \mathrm{g} / \mathrm{min}$. However, the main clinical challenge for intensive care physicians is predicting which patients are unlikely to survive ICU stay. This is especially relevant in resource-limited settings, due to the scarcity and cost of critical care. In this regard, the PPV for ICU mortality of inotropic support approaches $90 \%$ for both admission and 24-hour inotrope doses, with similar findings for a maximum inotrope dose $\geq 80 \mu \mathrm{g} / \mathrm{min}$. Similarly, the specificity for an admission or 24-hour cut-off of $60 \mu \mathrm{g} / \mathrm{min}$ is $96.9 \%$ and $96.8 \%$, respectively, implying a very low false-positive rate for ICU mortality.

With a mortality rate approaching $90 \%$ for an admission or 24-hour inotrope dose $\geq 60 \mu \mathrm{g} / \mathrm{min}$, the clinical and ethical question that needs to be considered is whether this is an appropriate ceiling for inotropic support. A clear maximum recommended dose of inotropic support would allow clinicians to triage patients on admission, or at least at 24 hours after admission. This would reduce patient exposure to unnecessary artificial life-sustaining therapy and reduce inappropriate utilisation of critical care resources. The value judgement to be made is whether $90 \%$ mortality provides adequate clinical certainty. For many clinicians, this would not be adequate certainty, with a single inotrope dose therefore being unlikely to replace clinical judgement. A counter argument is that a strong case would need to be made by a treating physician who wishes 
to continue with $>60 \mu \mathrm{g} / \mathrm{min}$ of inotropic support. With only a $10 \%$ chance of survival, it could be argued that ongoing artificial lifesustaining therapy is not ethically appropriate.

Direct comparisons with other studies in the field are difficult owing to differences in patient population and study methodology. The findings of this study are, however, broadly compatible with those of Benbenishty et al. ${ }^{[5]}$ Jenkins et al. ${ }^{[6]}$ Sviri et al. ${ }^{[7]}$ and Brown et al. ${ }^{[8]}$ but show higher mortality than those of Auchet et al. ${ }^{[9]}$ and DöppZemel and Groeneveld. ${ }^{[10]}$ These findings highlight the difficulties of applying studies from other settings to a specific clinical population and illustrate the importance of conducting locally relevant research.

Subgroup analysis suggests clinically relevant differences in response to inotropic support according to the primary pathology. While no survivors were noted who had been administered inotrope doses $>80 \mu \mathrm{g} / \mathrm{min}$ in sepsis and non-communicable disease, survival up to the maximum inotrope dose of $143 \mu \mathrm{g} / \mathrm{min}$ was seen in trauma. This is most likely due to trauma patients being younger and having fewer comorbidities, and most importantly, having a readily reversible underlying pathology. These subgroup differences should be considered the limitation of inotropic support, while more liberal use of higher thresholds in trauma patients is recommended.

\section{Study strengths and limitations}

This study has numerous strengths, most notably that it is the first such study in a resource-limited setting and in sub-Saharan Africa. It also explored early inotrope dose, the use of clinically relevant cut-off points to improve its clinical utility and potentially clinically relevant subgroup differences.

The study limitations include the retrospective nature and relatively small population size. The classification of the patient's shock state was particularly difficult from retrospective notes and, therefore, other than excluding patients with an apparent cardiogenic component, further categorisation of the shock state was not used. The single-centre nature of the study also limits the generalisability of the results. For this reason, a larger prospective multicentre study exploring these issues is strongly advised. The other factor that may have introduced bias into the study is the limitation of inotrope dose by the treating physician. While this was noted in only 3 patients (all of whom survived their ICU admission) due to the retrospective nature of the study, the limitations of inotropic support may have occurred, but were not documented in the clinical notes. The kinetics of inotropic support were not evaluated, and some factors, such as duration of peak inotropic support and changes in inotropic support, may have significant prognostic implications and warrant further investigation.

\section{Conclusions}

The study found early inotropic dose to be significantly associated with ICU mortality. There was also a statistically significant difference in median inotrope dose between survivors and non-survivors for admission, 24-hour and maximum inotrope doses. Low doses of inotropic support $(<13 \mu \mathrm{g} / \mathrm{min})$ are associated with high ICU survival
( $\geq 70 \%$ ), while high doses of inotropic support $(\geq 60 \mu \mathrm{g} / \mathrm{min})$ are associated with a mortality approaching $90 \%$ for both admission and 24-hour inotrope doses, with similar findings for a maximum inotrope dose $\geq 80 \mu \mathrm{g} / \mathrm{min}$. These findings suggest that early inotrope dose may be useful in ICU risk prediction. The results also suggest that high doses of inotropic support in patients with sepsis and non-communicable disease are unlikely to be beneficial, but more appropriate in the acute phase of trauma. Given the high volume of young patients who require ICU support in SA, further studies to validate these findings are recommended.

\section{Declaration. None.}

Acknowledgements. My deepest gratitude to my advisors, Drs K de Vasconcellos and D Skinner, for their continuous support and for making this research possible.

Author contributions. MA: study design, data collection and drafting of manuscript; and KdV: study design, data analysis and review of manuscript.

Funding. None.

Conflicts of interest. None.

1. Overgaard $\mathrm{CB}$, Dzavik V. Inotropes and vasopressors: Review of physiology and clinical use in cardiovascular disease. Circulation 2008;118(10):1047-1056. https://doi.org/10.1161/ use in cardiovascular

2. Rhodes A, Evans LE, Alhazzani W, et al. Surviving sepsis campaign: International Guidelines for Management of Sepsis and Septic Shock: 2016. Crit Care Med 2017;45(3):486-552. https://doi. org/10.1007/s00134-017-4683-6

3. De Vasconcellos K, Skinner DL. Hyperchloraemia is associated with acute kidney injury and mortality in the critically ill: A retrospective observational study in a multidisciplinary intensive care unit. J Crit Care 2018;45:45-51. https://doi.org/10.1016/j.jcrc.2018.01.019

4. Peake SL, Bailey M, Bellomo R, et al. Australasian resuscitation of sepsis evaluation (ARISE): A multi-centre, prospective, inception cohort study. Resuscitation 2009;80(7):811-818. https://doi. org/10.1016/j.resuscitation. 2009.03 .008 .

5. Benbenishty J, Weissman C, Sprung CL, Brodsky-Israeli M, Weiss Y. Characteristics of patients receiving vasopressors. Heart Lung 2011;40(3):247-252. https://doi.org/10.1016/j.hrtlng.2010.04.007

6. Jenkins C, Gomersall C, Leung P, Joynt G. Outcome of patients receiving high dose vasopressor . Jenkins C, Gomersall C, Leung P, Joynt G. Outcome of patients receiving high dose vasopressor
therapy: A retrospective cohort study. Anaesth Intensive Care 2009;37(2):286-289. https://doi.

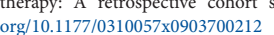

7. Sviri S, Hashoul J, Stav I, van Heerden P. Does high-dose vasopressor therapy in medical intensive care Sviri S, Hashoul J, Stav I, van Heerden P. Does high-dose vasopressor therapy in medical intensive care
patients indicate what we already suspect? J Crit Care 2014;29(1):157-160. https://doi.org/10.1016/j. jerc.2013.09.00

8. Brown SM, Lanspa MJ, Jones JP, et al. Survival after shock requiring high-dose vasopressor therapy. Chest 2013;143(3):664-671. https://doi.org/10.1378/chest.12-1106

9. Auchet T, Regnier M-A, Girerd N, Levy B. Outcome of patients with septic shock and high-dose vasopressor therapy. Ann Intensive Care 2017;7(1):43. https://doi.org/10.1186\%2Fs13613-017$0261-x$

10. Döpp-Zemel D, Groeneveld AJ. High-dose norepinephrine treatment: Determinants of mortality and futility in critically ill patients. Am J Crit Care 2013;22(1):22-32. https://doi.org/10.4037/ ajcc 2013748

11. Vincent J-L, Marshall JC, Namendys-Silva SA, et al. Assessment of the worldwide burden of critical illness: The intensive care over nations (ICON) audit. Lancet Respirat Med 2014;2(5):380-386. https:// doi.org/10.1016/s2213-2600(14)70061-x

12. Adhikari NKJ, Fowler RA, Bhagwanjee S, Rubenfeld GD. Critical care and the global burden of critical illness in adults. Lancet 2010;376(9749):1339-1346. https://doi.org/10.1016/s0140of critical illness

13. Wise R, de Vasconcellos K, Skinner D, et al. Outcomes 30 days after ICU admission: The 30DOS study South Afr J Anaesth Analg 2017;23(6):139-144. https://doi.org/10.1080/22201181.2017.1402553

14. Skinner DL, de Vasconcellos K, Wise R, et al. Critical care admission of South African (SA) surgical patients: Results of the SA Surgical Outcomes Study. S Afr Med J 2017;107(5):411-419. https://doi. org/10.7196/samj.2017.v107i5.11455

15. DeLong ER, DeLong DM, Clarke-Pearson DL. Comparing the areas under two or more correlated receiver operating characteristic curves: A nonparametric approach. Biometrics 1988;44(3):837-845.

Accepted 13 January 2021 